\title{
IS PORTFOLIO DIVERSIFICATION ACHIEVABLE WITHIN THE MEXICAN STOCK MARKET?
}

\author{
Iván Aguayo Guajardo* \\ Departamento de Contabilidad y Finanzas \\ Tecnológico de Monterrey, Campus Monterrey
}

(Received 14 January 2005, accepted 7 March 2005)

\begin{abstract}
Diversification is most of the times considered a characteristic of any stock market. Nevertheless, recent research questions this issue specifically regarding to emerging markets given the synchrony of the returns of its instruments and Mexico is placed in the eye of the storm within the top ten. This analysis finds, with the use of a specific model, that investors can reduce around $50 \%$ of the standard deviation of the returns of a portfolio increasing the number of stocks it contains. So this concern should not be a reason for investors to avoid investing in the BMV.
\end{abstract}

\section{Resumen}

La diversificación es la mayoría de las veces considerada una característica de cualquier mercado de valores. Sin embargo, investigación reciente cuestiona este tema específicamente con respecto a los mercados emergentes dada la sincronía en los rendimientos de sus instrumentos y México es puesto en el ojo de la tormenta dentro de los 10 con más alta sincronía. Este análisis encuentra, con el uso de un modelo específico, que los inversionistas pueden reducir alrededor del $50 \%$ de la desviación estándar de los rendimientos de un portafolio al aumentar el número de acciones contenidas. Así que esta preocupación no debería ser una razón para que los inversionistas eviten invertir en la BMV.

JEL classification: G11, G15, N26

Keywords: Portfolio Choice, Investment Decisions, International Financial Markets, Financial Economics

* Departamento de Contabilidad y Finanzas, Tecnológico de Monterrey, Campus Monterrey. Ave. Eugenio Garza Sada 2501 sur, c.p. 64849, Monterrey, N. L., México. Telephone: (81)8328-4196. E-mail: iaguayo@itesm.mx

The author is very grateful to the anonymous referees for their comments. 


\section{Introduction}

Extensive research exists regarding portfolio diversification. According to Evans and Archer (1968) diversifying beyond 10 or so securities might not have economic justification. Statman (1987) suggests that at least 30 stocks for a borrowing investor, and 40 for a lending investor, must be included in a welldiversified portfolio. Even though there exists a lot of discussion regarding the number of assets to be included in a portfolio to diversify it, it seems like there is no question regarding the feasibility of diversification. As stated by some, "Diversification is the only free lunch in Finance", up to some extent, of course.

Lately, some research regarding portfolio diversification in emerging markets has been conducted. Morck, Yeung,and Yu (2000) affirm that the systematic component of returns variation is large in emerging markets, and appears unrelated to fundamentals co-movement. Moreover, it appears that Mexico's Stock Exchange is ranked amongst the top 7 markets in terms of synchronous stock price movements. The question I addressed is to verify that portfolio diversification can be reached within the Mexican Stock Exchange (the Bolsa Mexicana de Valores-BMV) according to the Model proposed by Evans and Archer (1968).

Morck et al. (2000) state that the assumption that diversification is feasible in every stock market is not necessarily reliable, they find that stock prices move together more in poor economies than in rich economies. And, if low-income economies tend to be undiversified, firm-level earnings may be highly correlated because industry events are essentially market wide events. Therefore I present a test of the model proposed by Evans and Archer (1968) with a database of returns on Mexican stocks and revise their behavior.

This document is structured in the following manner. In section 2 a brief description of the Bolsa Mexicana de Valores is presented, and an excellent and thorough one is provided by Bhattacharya et al (2000). In Section 3 the data and the model to be tested herein are described. Section 4 documents the results regarding portfolio diversification and presents some concluding remarks.

\section{The Bolsa}

As described by Bhattacharya et al (2000) the Bolsa started activities in the mid $19^{\text {th }}$. Century mainly with mine shares, in Mexico City. Currently, there only exist two Mexican exchanges, the money and equities market, and the derivatives market. The latter started operations at the end of 1998 and as well as the BMV, the MEXDER, how it is known, is regulated by the National Banking and Securities Commission (CNBV). The MEXDER operates a relative small number of instruments and it was originally oriented to finance the small and median companies focusing mainly on the hedging interests of the importing companies. The BMV, as the Mexican Stock Exchange is currently known, defined its regulatory framework until 1975 by the Credit Organizations Law.

Companies issue equity of different types due to corporate governance issues and to comply with the regulations enforced by the CNBV. A-shares, may only be held by Mexican nationals, while B-shares are open to foreigners. Companies also issue L-shares which carry limited voting rights, and when only one series is issued is called a nominal series, commonly represented by a * Other types of series with limited voting rights, and with certain contract constraints 
are O's, C's, CPO's, ULD's, UCD's, and UBD's which are very common and not surprisingly, some of these series are the most traded given that the stocks owned by the controlling families are not traded often and account for the majority of the voting rights.

\section{Data and Model}

Data presented includes all stocks currently quoting with 10 years semiannual non-adjusted records of prices according to the Infosel Financiero (IF) database, stocks with incomplete records were not considered to avoid differences with the original model presented by Evans and Archer (1968) which includes calculations of returns and standard deviations of 10 years with semiannual information (20 semesters).

Issues regarding survivorship bias were overlooked assuming that those stocks do not represent the general behavior of the stocks under study. The first filter utilized to screen the data is that the stock is listing in the BMV in 2003 , and the second filter is that there exists 10 years of semiannual prices and no semester is "missing" in the IF database. Out of an initial list of 164 firms only 51 remain in the sample, totaling 59 different series.

One important difference with the original model is that there is only information available for 59 series of stocks, compared to the 470 stocks used for the analysis by Evans and Archer (1968) from the S\&P 500. 7 stocks provide more than one series, I decided to maintain them in the sample in order to increase the set of data from 51 to the 59 cited above.

Another difference is that non-adjusted prices are used to account for the semiannual returns. Table 1 presents the stocks and its series with the average semi-annual return over the 19 periods where the geometric mean return for security $k$, and its standard deviation of the logarithms of the value relatives were computed as follows:

$$
\begin{aligned}
& \bar{R}^{k}=\exp \left(\frac{1}{n} \times \sum_{i=1}^{n} \ln \frac{P_{i+1}^{k}}{P_{i}^{k}}\right), \quad \text { for } n=19, \text { and } k=1 \text { to } 59^{\text {th }}, \\
& S D^{k}=\sqrt{\frac{\sum_{i=1}^{n}\left(\ln \bar{R}_{k}-\ln R_{i}^{k}\right)^{2}}{n-1}}, \quad \text { for } n=19, \text { and } k=1 \text { to } 59^{\text {th }},
\end{aligned}
$$

With the values calculated for each security, 1,200 portfolios are formed with randomly selected stocks and considering proportional investments on each of the securities forming any given portfolio (naive portfolios). 60 runs were used for every portfolio size, totaling 1,200 portfolios (60 with one randomly selected stock, 60 with 2 randomly selected stocks, 60 with 3 randomly selected stocks, $\cdots$, and 60 with 20 randomly selected stocks). Returns for the portfolio are calculated as follows, where $m$ is the number of securities in the portfolio,

$$
\bar{R}_{i}=\frac{i}{m} \times \sum_{k=1}^{m} R_{i}^{k}, \quad \text { for } m=1 \text { to } 20
$$


Next, with the results obtained, portfolio geometric mean returns for the entire period and the portfolio standard deviations are calculated as follows,

$$
\begin{array}{rlr}
\bar{R}_{p} & =\exp \left(\frac{1}{n} \times \sum_{i=1}^{n} \ln \bar{R}_{i}\right), & \text { and } \\
S D_{p} & =\sqrt{\frac{\sum_{i=1}^{n}\left(\ln \bar{R}_{p}-\ln \bar{R}_{i}\right)^{2}}{n-1},} & \text { for } n=19 .
\end{array}
$$

Table 1 presents the results of the mean portfolio semi-annual returns and the portfolio standard, along with some of the randomly selected stock portfolios.

Table 1. Geometric mean semi-annual returns and the standard deviation of the logarithms of the value relatives of every security in the sample.

\begin{tabular}{|c|c|c|c|}
\hline Ticker & Series & $\bar{R}^{k}$ & $S D^{k}$ \\
\hline ACCELSA & $\mathrm{B}$ & $-4.54 \%$ & 0.632 \\
ALFA & $\mathrm{A}$ & $-0.28 \%$ & 0.432 \\
APASCO & $*$ & $7.23 \%$ & 0.259 \\
ARGOS & $\mathrm{B}$ & $11.52 \%$ & 0.354 \\
BEVIDES & $\mathrm{B}$ & $-6.50 \%$ & 0.409 \\
BIMBO & $\mathrm{A}$ & $0.22 \%$ & 0.423 \\
CEMEX & CPO & $-0.49 \%$ & 0.443 \\
CERAMIC & ULD & $-2.36 \%$ & 0.264 \\
COMERCI & UBC & $-0.19 \%$ & 0.217 \\
CONTAL & $*$ & $4.86 \%$ & 0.327 \\
CYDSASA & $\mathrm{A}$ & $-8.22 \%$ & 0.403 \\
DESC & $\mathrm{A}$ & $-4.77 \%$ & 0.451 \\
DESC & $\mathrm{B}$ & $-4.83 \%$ & 0.511 \\
DESC & $\mathrm{C}$ & $-5.28 \%$ & 0.489 \\
EMPAQ & $\mathrm{B}$ & $-3.93 \%$ & 0.399 \\
FEMSA & $\mathrm{UBD}$ & $6.31 \%$ & 0.712 \\
GACCION & $\mathrm{B}$ & $-2.31 \%$ & 0.238 \\
GCARSO & $\mathrm{A} 1$ & $2.16 \%$ & 0.266 \\
GCC & $*$ & $6.17 \%$ & 0.246 \\
GENSEG & $\mathrm{B}$ & $6.57 \%$ & 0.193 \\
GEUPEC & $\mathrm{B}$ & $4.36 \%$ & 0.184 \\
GFBB & $\mathrm{B}$ & $3.86 \%$ & 0.311 \\
GFBITAL & $\mathrm{O}$ & $3.96 \%$ & 0.289 \\
GFINBUR & $\mathrm{O}$ & $1.97 \%$ & 0.386 \\
GFINTER & $\mathrm{O}$ & $-6.60 \%$ & 0.273 \\
GFMULTI & $\mathrm{O}$ & $-4.36 \%$ & 0.595 \\
GIGANTE & $*$ & $6.10 \%$ & 0.359 \\
GISSA & $*$ & $-4.96 \%$ & 0.459 \\
GMARTI & $*$ & $4.61 \%$ & 0.240 \\
GMODERN & $*$ & $8.71 \%$ & 0.279 \\
\hline
\end{tabular}


Table 1. (continue).

\begin{tabular}{|c|c|c|c|}
\hline Ticker & Series & $\bar{R}^{k}$ & $S D^{k}$ \\
\hline GPH & 1 & $-13.36 \%$ & 0.876 \\
HERDEZ & $*$ & $1.40 \%$ & 0.308 \\
ICA & $*$ & $-16.82 \%$ & 0.556 \\
ICH & $\mathrm{B}$ & $10.80 \%$ & 0.350 \\
KIMBER & $\mathrm{A}$ & $-1.82 \%$ & 0.431 \\
KIMBER & $\mathrm{B}$ & $-1.71 \%$ & 0.460 \\
LAMOSA & $\mathrm{B}$ & $-4.92 \%$ & 0.461 \\
LIVEPOL & 1 & $6.69 \%$ & 0.211 \\
LIVEPOL & $\mathrm{C}-1$ & $6.86 \%$ & 0.218 \\
MASECA & $\mathrm{B}$ & $1.53 \%$ & 0.355 \\
NADRO & $\mathrm{B}$ & $-5.27 \%$ & 0.387 \\
PARRAS & $*$ & $-4.91 \%$ & 0.290 \\
PE & $*$ & $6.24 \%$ & 0.387 \\
POSADAS & $\mathrm{A}$ & $3.99 \%$ & 0.269 \\
POSADAS & $\mathrm{L}$ & $3.45 \%$ & 0.270 \\
SANLUIS & $\mathrm{A}$ & $5.27 \%$ & 0.763 \\
SANMEX & $\mathrm{B}$ & $1.48 \%$ & 0.760 \\
SAVIA & $\mathrm{A}$ & $-12.79 \%$ & 0.607 \\
SORIANA & $\mathrm{B}$ & $11.59 \%$ & 0.275 \\
SYNKRO & $\mathrm{A}$ & $-17.21 \%$ & 0.722 \\
SYNKRO & $\mathrm{C}$ & $-16.05 \%$ & 0.841 \\
TAMSA & $*$ & $1.18 \%$ & 0.267 \\
TELMEX & $\mathrm{A}$ & $4.45 \%$ & 0.267 \\
TELMEX & $\mathrm{L}$ & $4.36 \%$ & 0.266 \\
TMM & $\mathrm{A}$ & $3.98 \%$ & 0.279 \\
VALUEGF & $\mathrm{O}$ & $-9.96 \%$ & 0.482 \\
VITRO & $\mathrm{A}$ & $-4.14 \%$ & 0.344 \\
WALMEX & $\mathrm{C}$ & $6.68 \%$ & 0.235 \\
WALMEX & $\mathrm{L}$ & $7.05 \%$ & 0.249 \\
\hline
\end{tabular}

* Nominal series of stocks are used when only one type of series is issued. As described by Bhattacharya et al. (2000) the most popular types of outstanding shares are the A-shares, B-shares and L-shares. The difference between the series resides in the legal ownership and the voting rights mainly.

Results in Table 2 provide evidence of some consistency with a diversification behavior, it seems like even though there is strong synchronicity among returns of the stocks, it is still valid the assumption that portfolio diversification can be achieved increasing the number of stocks in the portfolio. Despite an immediate increase in the standard deviation of the portfolio, it starts decreasing as portfolio size increases. 
Table 2. Portfolio selection process, mean portfolio return and portfolio standard deviation (example of one portfolio with securities presented by identification).

\begin{tabular}{|c|c|c|c|c|c|c|c|c|c|}
\hline & 1 & 2 & 3 & 4 & 5 & . & . & . & 20 \\
\hline 1 & 4 & 18 & 26 & 32 & 54 & . & . & . & 14 \\
\hline 2 & & 46 & 40 & 26 & 34 & . & . & . & 44 \\
\hline 3 & & & 30 & 31 & 15 & . & . & . & 10 \\
\hline 4 & & & & 14 & 51 & . & . & . & 17 \\
\hline 5 & & & & & 5 & $\cdot$ & . & . & 8 \\
\hline . & & & & & & . & . & . & . \\
\hline . & & & & & & & . & . & . \\
\hline . & & & & & & & & . & . \\
\hline 20 & & & & & & . & . & . & 3 \\
\hline $\bar{R}_{p}$ & .1152 & .0983 & .0620 & .0257 & . & . & . & . & .0429 \\
\hline$S D_{p}$ & .3539 & .4762 & .2829 & .2672 & . & . & $\because$ & . & .1655 \\
\hline
\end{tabular}

Note that security number 26 is part of the portfolio with 3 stocks and it also appears as part of the portfolio with 4 stocks, and security number 14 is part of the portfolio with 4 stocks as well as of the portfolio with 20 stocks. There are only 59 stocks available, so selection without replacement was not an option.

A couple of differences were made compared to the Evans and Archer (1968) analysis: a) given the number of securities in the sample, eventhough a security was selected in a particular run, this security was still eligible for further consideration in constructing the remaining of the 20 portfolios (portfolios with 1 stock to portfolios with 20 stocks), and b) only portfolio sizes from 1 to 20 stocks instead of 40 were built since as one of Statman's (1987) critics points out, this model might exaggerate the rate of decline in portfolio risk as exposed by Bird and Tippett (1986).

The main concern of this study is to verify that diversification can be achievable, so if this model magnifies the effect of diversification it will allow us to find a great degree of diversification with a small number of stocks

\section{Results}

The portfolios were next examined with the same hypothesized relationship as the one in Evans and Archer (1968) "-decreasing portfolio standard deviation to an asymptote as diversification increases", and just as well the regression analysis was performed fitting by least squares the regression function (the order of the factors slightly altered):

$$
Y=\beta_{0}+\beta_{1} / X \text {. }
$$


Where $X$ represents the size of the portfolio, and $Y$ represents the obtained mean portfolio standard deviation for each of the 1,200 portfolios ranging in size from 1 to 20 stocks (60 of each one).

The estimated equation obtained is of the form

$$
Y=.1900219+.2055461 / X
$$

Where $\beta_{0}=.1900219$, and $\beta_{1}=.2055461$, with $T$-values of 76.25 and 23.30 respectively, and a R-squared of .311866 with a correlation coefficient between $Y$ and $X$ of .5584 . The F-test of the estimated model is 542.94 , so it seems to be a solid model, and normality, mean zero and independence of the residuals appears not to be a problem.

Contrary to what Morck et al. (2000) would expect, diversification is still achievable in the BMV, around $50 \%$ of the risk measure disappears investing in more than 12 stocks or so according to this model.

Nevertheless, one of the stocks, Grupo de Embotelladoras Unidas, S.A. de C.V. (GEUPEC serie B), shows a lower standard deviation with .183621, than the standard deviation of the IPC with .187274 which not necessarily includes it.

Figure 1. Portfolio Diversification.
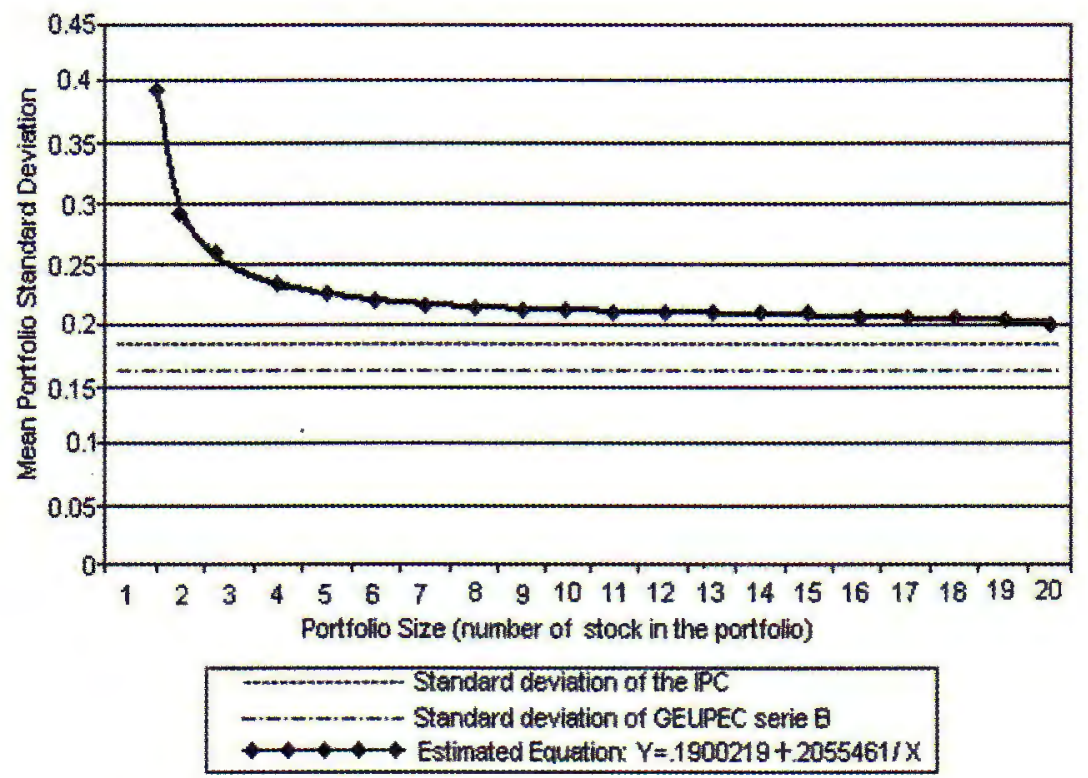

The mean standard deviation of the IPC over the same period is .187274 . The IPC is referred to as the Mexican Stock Market Index and is constructed of 30 to 35 stocks in a value weighted average manner of the most traded stocks over every period. GEUPEC serie B maintains a lower standard deviation than the average of the IPC, which does not necessarily includes it. 
Further research regarding portfolio diversification is being conducted, and results do not seem to vary significantly. However, there is a lot of work to be done regarding the reasons why Mexican investors do not invest a greater percentage of their portfolios in the domestic stock market, if any.

\section{References}

Bhattacharya, U., H. Daouk, B. Jorgenson, and C. Kehr (2000). When an event is not an Event: the Curious Case of an Emerging Market. Journal of Financial Economics 55, pp. 69-101.

Bird, R. and M. Tippett (1986). Naive Diversification and Portfolio Risk: A Note. Management Science, 32, 244-251.

Evans, J. L. and S. H. Archer (1968). Diversification and the Reduction of Dispersion: an Empirical Analysis. Journal of Finance, 23, pp. 761-767.

Harvey, C. R. (1995). Predictable Risk and Returns in Emerging Markets. Review of Financial Studies, 8, pp. 773-816.

Morck, R., B. Yeung, and W. Yu (2000). The Information Content of Stock Markets: Why do Emerging Markets have Synchronous Stock Price Movements. Journal of Financial Economics, 58, pp. 215-260.

Statman, M. (1987). How many Stocks Make a Diversified Portfolio? Journal of Financial and Quantitative Analysis, 22, pp. 353-363. 